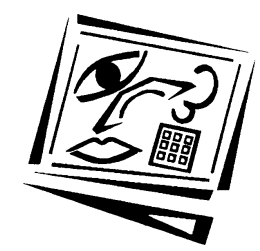

\title{
My.monash: Supporting students and staff in teaching, learning and administration
}

\author{
David M Kennedy, Len Webster, Robyn Benson, \\ Di James and Nathan Bailey \\ Monash University
}

\begin{abstract}
The my.monash Portal (Portal) provides a virtual gateway to support student centred flexible learning by coordinating many of the university's key resources to meet the needs of students and staff. The Portal is intended to help deliver innovative learning programs, foster opportunities to undertake research, increase flexibility of access to resources and services, support asynchronous approaches to teaching and learning, and allow online teaching and learning environments to be more responsive to changing student needs. In essence, it is part of a recent movement in higher education towards providing more complete, holistic online environments for students and staff by converging a number of technologies. The project has been developed with an innovative software design model (extreme programming) that involves rapid prototyping, in which iterative and continuous evaluation by staff and students is used to inform all aspects of the project's design and development. This has resulted in significant collaborative activities across a wide cross section of the university community. The paper will address each of these aspects in turn, concluding with the results of the evaluation processes and future directions for the development of the Portal.
\end{abstract}

\section{Introduction}

Universities across Australia are setting up virtual gateways for their staff and students, allowing them to enter a new world where academic, administrative and support resources are all available online. This is encapsulated by Maslen (2000, p.10) who said in describing a virtual gateway, 'one moment [students] may be working in a face to face environment, then looking for electronic resources in the library, contacting fellow students via email, completing online unit components or electronically changing their personal details'. Monash University is a large institution with campuses or affiliates in Australia, Malaysia, South Africa, Italy and the United Kingdom. The use of technology based 
resources is increasing at Monash because of changes in higher education attributed (but not limited) to, funding, diverse student backgrounds (Australian Vice-Chancellors' Committee, 1996), changing student expectations and lifestyles, new developments in technology and opportunities for improved approaches to learning and teaching.

The process of developing appropriate technology based tools to address some of these changes has become an institutional point of focus rather than merely the domain of individual departments or faculties. As the use of computer based technology has moved from the fringes of higher education to become a core component of course materials, administrative functions and communication, issues of software quality, student learning outcomes and integration of computer facilitated learning (CFL) modules within the (whole) curriculum context have become paramount (McNaught, Phillips, Rossiter \& Winn, 2000). The my.monash Portal (Portal) project is one strategy intended to address this increasingly diverse set of needs of students and staff in a rapidly changing global context. The Portal was released for widespread use in the university in July 2000 after an 18 month collaborative project involving staff and students at the university. This paper reports on the functionality, developmental model, and results of extensive evaluations involved in the construction of the Portal.

\section{Meeting institutional, student and staff needs}

The problem faced by any university ... is how to structure itself so that its central academic activity is facilitated, not undermined, by technological developments (Laurillard \& Margetson, 1997, p. 4).

The Portal developed from a proposal in January 1999 to create a virtual gateway to support the strategic priorities of the University by:

- using new technologies to improve learning and teaching by enhancing student learning methodologies and increasing the pedagogical options, integration and scope of the teaching and learning environment;

- providing students with greater choice in terms of the place, pace, time and style of learning and interaction with teachers and other students;

- developing more flexible programs, award structures, accelerated study options and articulation with other institutions.

The broad directions given to the Portal team were to develop a consistent and reliable institutional interface for students and staff, encompassing both administrative and educational functions. Students should be able to move from administrative to educational needs seamlessly. In short, the 
university required a systems approach that was holistic, rather than segmented, with the functionality to support and facilitate student learning through the use of computer based technologies.

The planning for the Portal included a review of other university Intranet and Portal sites in Australia and overseas. Only two universities were identified (at the time) as being involved in Portal development. These were the:

- University of California at Los Angeles (UCLA) whose recently released portal appeared to meet the objectives established for the My.monash project; and

- University of Sydney, whose portal was focused on administrative functionalities only.

Discussions with both universities indicated that portal development was in its infancy and no useful software products were available. A decision was made at Monash to develop the trial system in house and to use an iterative/ evolutionary development process, at least for the initial development phase. In the first instance, focus groups formed a key role in determining the initial functions of the Portal. As a result, it was initially proposed that the Portal include the following (within a consistent user interface), regardless of the role of the user.

1. A common student environment to enable:

- individual customisation, and authorisation;

- support for student learning, based on interaction with peers and staff using email, discussion forums (newsgroups), video/audio/text based conferencing;

- assignment submission and feedback;

- access to educational resources, advisory services, and information and library services; and

- access to administrative services, including enrolment, fee payment, record checks and amendment.

2. A common staff environment to enable:

- individual customisation and authorisation;

- preparation and publishing of educational materials ranging from authoring HTML pages to 'off the shelf' systems; 
- interaction with peers and students, including tutorial based discussion groups, workgroup support (email, directory service, discussion forums), and video/audio/text based conferencing;

- educational management, including distance education management tools, workgroup management, assignment and assessment facilities;

- access to administrative services, information and library services.

\section{Design and development}

In reality, complex systems evolve iteratively, even incrementally. It is for this reason that a large segment of the software engineering community is moving toward evolutionary models of software development (Pressman, 1997, p.832).

\section{The need for a team approach}

The scale of the Portal project and its key relationship to University infrastructure necessitated a collaborative approach from the start, involving a core multidisciplinary team of educational, information technology and administrative staff (including project management expertise). The core group subsequently drew on the wider University community as part of a broader ongoing design and evaluation team. This was accomplished by establishing a reference group and student quality assurance teams in conjunction with two core sub-groups within the project team (consisting of technical development staff and client liaison staff). One of the core sub-groups tasks was to establish effective communication mechanisms, and work between the end users, educational experts and the technicians.

The Portal needed to meet crucial institutional and pedagogical requirements. These needs were met through collaborative and team based approaches. The collaborative processes extended out from the development team to encompass a range of potential user groups in the University. A critical decision affecting the outcomes and success of the Portal environment was the selection of a development model. The main design philosophy employed by the Portal team was that the Portal be intuitive, user focused and useful. This, by necessity, required the input of individuals with a range of specialist skills, including evaluation (Kennedy, 1999), project management (Phillips, 1997), and educational design (Kennedy \& McNaught, 1997). The strong team dynamic fostered good communication within and outside the team to produce high quality outcomes for both students and academics. Using this process, the Portal has now become an integrated one stop point for Monash staff and students (Bailey, Bromage \& Creer, 2000) providing: 
- a personalised Web page;

- a single Internet gateway to the university, with links to enrolled subjects, library information, student administration and support services;

- an environment that may be customised by each student;

- subject pages that are customisable by teachers; and

- links (at the subject level) to online computer mediated discussion groups, subject web sites, subject specific Uniform Resource Locators (URLs), and subject specific library links (including past examination papers).

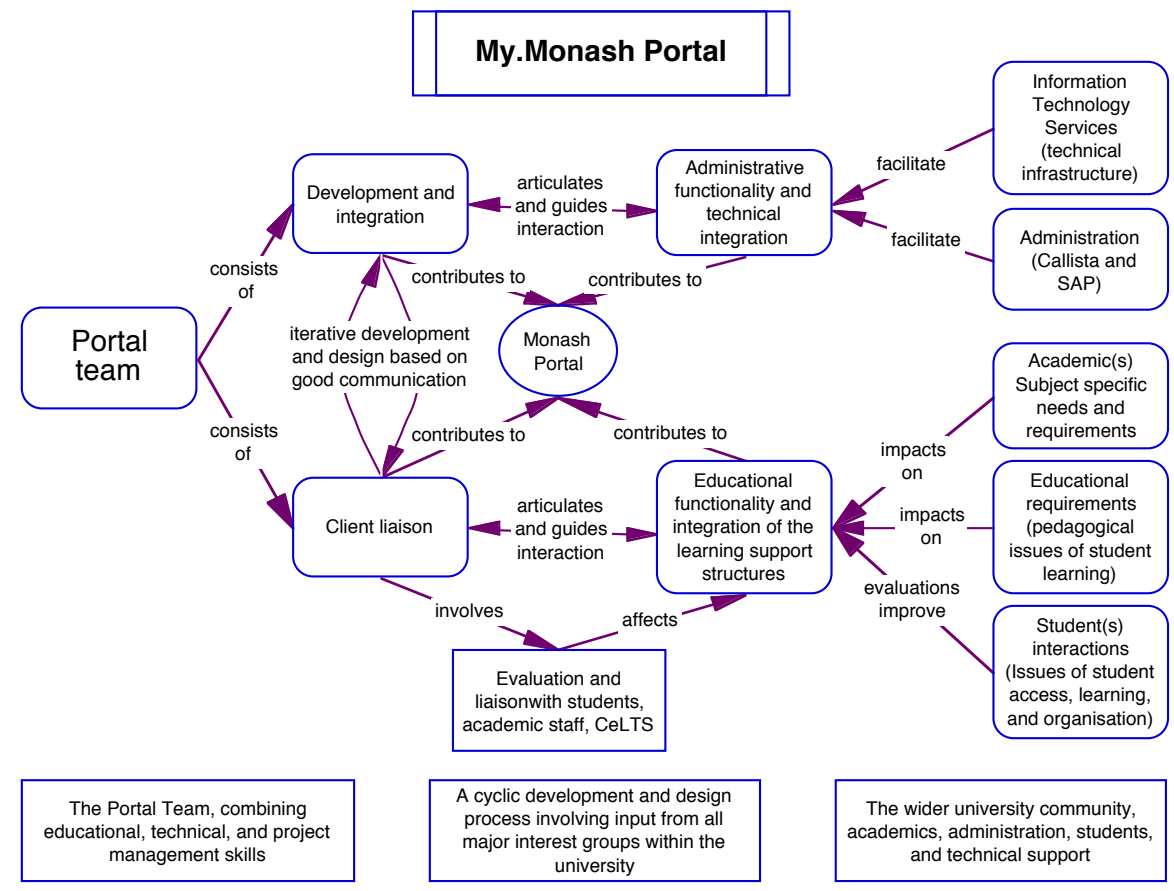

Figure 1: The cyclical design and development process implemented to ensure input from all stakeholders

The model of software engineering chosen by the Portal team reflected the collaborative approach to the developmental process adopted by the team in order to meet its goals and communicate with potential users. In Figure 1, the framework that was established is shown, together with the communication pathways that enabled the Portal team to receive input and feedback from a wide cross section of the university community (in 
Figure 1 CeLTS is the Centre for Learning and Teaching Support, Callista is the student administration system and SAP is the university accounting and financial system). Figure 1 provides an overview of the:

- communication mechanisms between the members of the Portal team;

- communication between the Portal team and the Monash community;

- opportunities for evaluation and feedback to support the development process; and

- iterative/cyclic approach to the design and development of the Portal.

The design brief required that the Portal graphics be kept to a minimum to facilitate fast download times. A page from the current version of the Portal system is shown in Figure 2 (for the first author). There are links to an authorised subject (MPH2066), Personal Info, News and Weather, Search functions and the Library on the left, for example. The main pane has important semester dates listed, news articles available online and Student links.

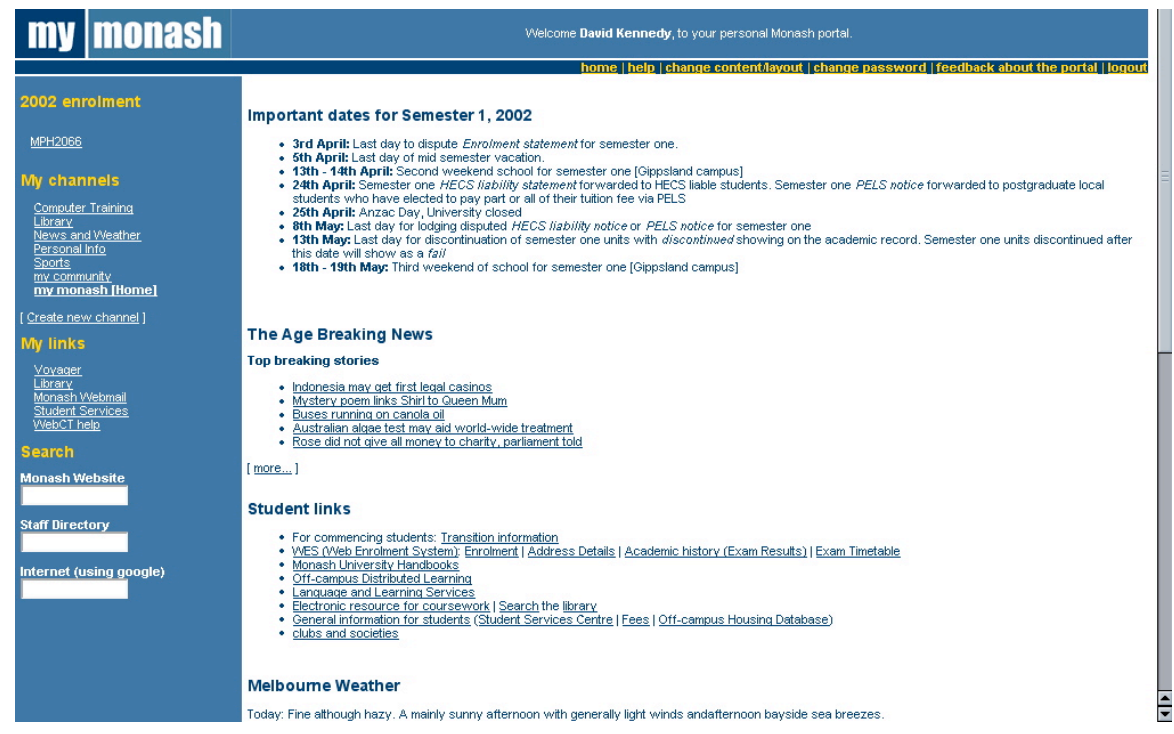

Figure 2: An example of a my.monash Portal page

\section{A pedagogical perspective}

Another important principle in the design brief was to enable student control of the learning environment (customisation), reflecting the 
acceptance of a broadly constructivist view of learning, in which knowledge is individually constructed and socially co-constructed by learners based on their interpretations of experiences in the world (Biggs, 1999; Jonassen \& Rohrer-Murphy, 1999; Kennedy \& McNaught, 1997). One important aspect of the Portal was the integration of computer mediated communication (asynchronous discussion groups) to support more flexible student learning environments. The incorporation of online discussion groups has been shown to foster collaborative learning (Agostino, Lefoe \& Hedberg, 1997), improve flexibility in teaching and learning (Freeman, 1997), support problem based learning (Oliver \& Omari, 1999), and facilitate role playing activities (Freeman \& Capper, 1999; Naidu, Ip \& Linser, 2000).

\section{Evaluation as a design process}

Phillips et. al. (2000) provided a model of formative and summative evaluation. This model is based upon the work of Bain (1999) and Alexander \& Hedberg (1994) that addresses interface issues and student learning outcomes in the development of computer supported learning environments such as the Portal. They argue that early formative evaluation with the target group, or groups, will alleviate many potential design problems. The value of this approach in the context of higher education is supported by Moonen \& Schoenmaker (1992, p. 118) who observed that the interaction of the user with new software is often very difficult to specify precisely, and evaluation of an early prototype 'almost always elicits comments and suggestions for alterations'. It is not too strong a statement to say that formative evaluation is fundamental in CFL development if a quality product is to be delivered (Burkhardt, 1992). The Portal has incorporated feedback from all stakeholders in the University to guide and inform the development (see Figure 1).

The development of the Portal utilised a revised version of an evolutionary software engineering model based upon the incremental approach. Such models have frameworks that are iterative, involve the target group early, and are used in situations requiring rapid development (Pressman, 1997). The actual approach used, called Extreme Programming $(\mathrm{XP})$, relied on simplicity, unit testing, programming in pairs, communal ownership of code, and customer input on software to motivate code improvement during the development process (Beck, 1999). This model of software development resulted in short development times, robust software, and good models of communication both within the team and the wider University community. 
The core functionalities of the Portal were devised using a scenario based approach (Carroll, 1995) where teaching academics, the Portal team and students developed descriptions of what functionalities were needed to produce an effective educational and administrative product. Formative evaluation with potential users (students and academic staff) was undertaken very early in the life of the project. From the evaluation feedback, additional functionalities were then added to the Portal environment (see Figure 1). In this project, each release of the Portal was as robust as the programming team could achieve leading to very positive student and staff feedback. There were few implementation problems due to rigorous quality assurance testing conducted by a group of students employed to both 'break' the system and to comment on its usefulness and usability, prior to its initial trial phase and the release. This project is now in a 'post development' phase. However, the development model selected to ensure a robust, highly functional product in the first instance, also ensures that the Portal remains a viable, integrated part of the student learning environment at the university (cf. Alexander, McKenzie \& Geissinger, 1998). Bailey, Bromage \& Creer (2000) provide a full technical description of the Portal's functionalities.

\section{Evaluation}

Evaluation of the Portal was integral to the development process. There were three interlocking stages with each undergoing evaluation. The phases involved an initial design, followed by a trial phase and then a formal release. Initially, these phases focused primarily on learning and teaching functionality. However, since the release in July 2000, administration and support functionalities have been incorporated. The evaluation component of this paper is presented as a unified whole because of the inherently close relationship between the programming efforts and the formative evaluation that guided and supported the process.

A careful selection of students and staff enabled extensive, wide ranging and realistic evaluation of the system. The formative evaluations of the Portal involved peer review, a walk through of each iteration, questionnaires, observation of target groups using the software, user tracking and interviews (individually or in focus groups) with potential users (Stade, Murphy, Webster \& James, 1999). The student and staff evaluations informed all aspects of the design, including the user interface, navigation, and how the software functionality supported student learning (Reiser \& Kegelmann, 1996). Evaluation involved: 
- focus groups of students and staff;

- teaching academics (identified as being already engaged in using technology to support teaching and learning), who completed an open ended questionnaire;

- an online discussion group intended to provide immediate and direct feedback from staff and students;

- academic and general staff, involved in workshops designed to help them incorporate threaded discussion groups into their teaching and learning (via the Portal); and

- the generation of quantitative usage data from the Portal server and unsolicited feedback from a trial group of over 1200 students enrolled in a variety of modes and subjects including mixed mode, multicampus, on campus, distance education and flexible learning subjects in semester 2 July 1999.

Feedback from each of these evaluation processes is examined in turn, briefly. Initially, interviews with 16 students and eight staff to assess Portal functionality were undertaken with the first prototype. This evaluation also informed the design of questions for the future surveying of staff and students during 2000/2001. The evaluation used the following inputs:

- Students and staff who could not attend the focus groups were contacted by telephone. Their responses were used to guide discussions in subsequent focus groups.

- A small student focus group from a Philosophy subject was invited to discuss Portal functionality and issues.

- Selected staff members were telephone surveyed on a number of Portal issues.

Staff and students were asked the same set of general questions except that questions for staff were focused on the conduct of the subject rather than learning. All but one student found the Portal features useful to their learning. The main use was to access the subject discussion groups:

\footnotetext{
...the access to the different discussion [groups] provided access to different points of view. Also it allowed feedback on our own opinions and ideas from the other students. (Student, 1999).
}

The Portal also provided improved access to subject resources including, past examinations, assignment cover sheets, web resources and Monash resources. Further, access to the Portal was identified as being through both on campus computer labs, kiosks and external dial in from home or 
other locations, although the predominant use during these initial phases was on campus.

With regard to Portal functionality, several significant issues were raised, the most prevalent being the functionality of the discussion group interface. This resulted in substantive changes to the interface of the discussion groups prior to the major release.

A number of additions to the Portal functionality were also suggested by several students to further support their learning. These included interactive chat with the tutor, a capability to download lecture notes, and the ability of tutors to issue reminders to students. A timetable function was also suggested to detail all the lectures and activities for the subjects in which the student is enrolled. Staff evaluators also supported these views. The changes recommended by the evaluation were either incorporated for the release in July 2000 or are still being developed in conjunction with other areas of the University. Other comments effecting development received at this time included:

I believe the portal project is a fantastic idea. With so much dependence on the web for information, it is great students can sieve through or bypass all the info irrelevant to them and have immediate access to the information which they require. The ability to customise your portal adds to the control the student has over THEIR web page. It prevents important information from being overlooked or missed due to overload of information. (BA, student, 1999).

I think this is a great service. I have added it to my favourites list. It is a fantastic diving board to access Monash information...(BB, student, 1999).

... please don't ever let this project stop.....I think everyone at Monash [should] have the privilege of experiencing this (JB, student, 1999). ... I just think that it is an absolutely wonderful idea. Makes everything a whole lot easier. I think that everyone should have one of these.... (EM, student, 1999).

The simplicity (from a teaching and learning perspective) of integrating the Portal based discussion groups was evaluated favourably by 57 academics and general staff involved in seven half day workshops to introduce the use of discussion groups within a subject Portal subject page. Over 80 percent of participants indicated that the Portal was very simple and straightforward to use, an important criterion for successful use (Kennedy, McNaught \& Nicolettou, 1998).

One subject evaluated, HED5001 Designing for Learning, a subject in the Graduate Certificate in Higher Education, incorporated a substantial 
online component that involved the Portal and an online discussion group. Some of the comments and recommendations received from this subject included:

- Overall, the analysis indicated that the online discussion forum provided a medium for 'lively' interaction between students and staff. This discussion was highly interactive (rather than many postings of independent statements), and relevant to the course content. The discussion forum was evidently not used for social interaction, nor very often for administrative or technical support.

- There was an overall sense that the students were using the discussion forum for two purposes: on a theoretical and conceptual level the discussion was used to debate content covered in the course; and on a practical level to discuss problems and swap strategies for improving the participants' own teaching practice.

The portal will be useful to both students and staff in a course context by providing easy access to course material and relevant links. The ease of communicating with staff (through email) and other students (with discussion forums) is a bonus. The features already planned in terms of students setting up their own discussion forums, or for academics to set up smaller groups for discussion will be a potentially useful tool for managing and helping the group process. In terms of technological support this is a great start to thinking about flexibility (AC, staff evaluator, 1999).

An open ended questionnaire was distributed to ten staff who taught using a Portal supported subject in Semester 1,2000. The responses form a series of vignettes that illustrate the impact of the Portal in providing a mechanism for online learning that did not previously exist at the University. The results indicate that as staff and students became more familiar with the Portal, new dimensions of its uses for learning were explored, and unforeseen pedagogical benefits emerged, including its use (particularly the online discussion groups) as a central tier for developing flexible learning environments.

The portal enabled an important link to develop between a diverse group of students who all worked and studied in different areas of nursing practice. It also provided the medium to better enable a transfer of theory to practice. (AB, lecturer, 2000).

[The Portal enhances the] ability to work in groups at a distance. Ability to read other student's input, and hence develop ideas by considering other students points of view is very useful (MI, lecturer, 2000). 
In particular, given that the two subjects were Asian Studies subjects, it was a great opportunity to students from Malaysia and Australia to share the perspectives of their country on the same issues (HR, lecturer, 2000).

I observed that it [the Portal] served as an ice breaker because the students 'knew' each other and had communicated with each other before they met on the course (a Block week of teaching). It facilitated [face to face] discussion right away without the need for them to introduce themselves. The ones who had been active seemed to be a bit more into the subject than the ones who had not taken part (EF, lecturer, 2000).

[The Portal provided] a means of fostering communication between students on three geographically separate campuses. (HR, lecturer, 2000)

Quantitative data was also collected and analysed. For example, there have been more than 4000 staff members and 17,000 students who have accessed the Portal. More than 180 subjects are directly linked to the Portal and many other subjects have resources that are accessed via the Portal. On the release day, over 1800 people accessed the Portal. Typically, in the early phases of use more than 1000 people access the Portal every day. (Portal statistics report, August 2000).

A qualitative account of a variety of components and services offered through the Portal is available through archived comments by users of the Portal received via an in-built feedback mechanism. The team uses these, along with other forms of feedback, as a way of continually formatively evaluating the Portal and bringing issues to the attention of the development team. Table 1 shows the breakdown of unsolicited comments (mostly critical of problems encountered, but some requesting improvements) from students $(67 \%)$ and staff $(31 \%)$ via a discussion group incorporated into the first release of the Portal. The italicised comments in parenthesis indicate changes that resulted from the feedback ( $N$ is the number of comments received).

\section{Overall impact of the project, proposed and ongoing developments}

Between January and May 2001, over 31,000 students and 5,000 staff accessed the Portal. More than 9,000 students become frequent users after the full release of the Portal, using it to access email, student records and administration, and subject based discussion groups (in order of usage). Following the initial suite of evaluations, changes and additional functionalities identified were implemented and ongoing development has continued in 2001 and 2002. By semester $12002,95 \%$ of students and $35 \%$ of staff access the Portal on a weekly basis. There are now (early 2002) over 2000 subjects available via the Portal. 
Table 1: Comments from staff and students after the initial release of the Portal

\begin{tabular}{|l|c|l|}
\hline $\begin{array}{c}\text { Category of } \\
\text { feedback }\end{array}$ & $N$ & \multicolumn{1}{|c|}{ Example of feedback received (and changes made) } \\
\hline General Portal & 50 & $\begin{array}{l}\text { (The) drop down list of staff. Students can keep certain } \\
\text { staff in personal address book. } \\
\text { Great idea, very convenient, and the customisation feature } \\
\text { is great. } \\
\text { (I have much) better access to resources (now). }\end{array}$ \\
\hline Subjects & 24 & $\begin{array}{l}\text { The subject Portal pages need to open as a new window so } \\
\text { the Portal is not lost. (not implemented following usability } \\
\text { testing) }\end{array}$ \\
\hline Customisation & 17 & $\begin{array}{l}\text { It would be good if I could use an external email address } \\
\text { within the Portal. } \\
\text { It would be good to have email via the Portal. (since } \\
\text { implemented for staff, and students can set a forwarding } \\
\text { address) }\end{array}$ \\
\hline Discussion & 15 & $\begin{array}{l}\text { Unsure how to visit newsgroups. (online documentation has } \\
\text { been created to support getting started with the Portal) } \\
\text { Can't find reply emails from lecturer. }\end{array}$ \\
\hline Technical & 10 & $\begin{array}{l}\text { I can't use the service provider recommended - can't } \\
\text { access Library information (a problem with certain Internet } \\
\text { Service Providers which has since been rectified). }\end{array}$ \\
\hline Look and feel & 6 & $\begin{array}{l}\text { (Need) a more visual approach to home page interface (the } \\
\text { Portal has had a series of interface designs in response to } \\
\text { feedback) }\end{array}$ \\
\hline Navigation & 6 & $\begin{array}{l}\text { No way back from the Portal to the Calendar. } \\
\text { (Is there) any way to log out of the Portal? (since } \\
\text { implemented) }\end{array}$ \\
\hline Woather & 3 & \begin{tabular}{l} 
Good to have access to forecasts. \\
\hline
\end{tabular} \\
\hline
\end{tabular}

Two recent additions to the Portal functionality are the communication channel and the personal information channel. The first is intended to support special interest groups amongst students, rather than just academic and administrative functions. For example, there is the student music disc group with interest in music CD-ROMs - a discussion forum with hundreds of postings in the first two months. Also available on this channel is an online version of the daily campus news and events, including live performances by music groups on campus. The second channel provides more pragmatic personalised information for students including disk quota storage space available, and library details (books on loan, overdue items and fines imposed). 


\section{Integration of the Portal with the university LMS}

The current major task of the development team is the integration of WebCT (Campus Edition), and Interlearn (McKenzie \& Murphy, 2000), two Learning Management Systems (LMS) in use at Monash, into the existing Portal environment, to provide more direct support for teaching and learning activities. The intention is to have a single username and password for student and staff logon for all academic and administrative functions of the Portal (Figure 2).

All evaluations of the Portal to date indicate that this is a worthwhile and useful project for both staff and students of the University in facilitating and supporting teaching and learning using web based technologies. The Portal will continue to evolve as ongoing evaluation occurs, resulting in new software releases with additional functionalities, reflecting the ongoing collaborative nature of this innovative development. The convergence of the Portal and other proprietary products (eg., WebCT and InterLearn) will enable more diverse administrative and educational functions to be supported.

\section{References}

Agostino, S., Lefoe, G. \& Hedberg, J. (1997, 16 July). Online collaboration for learning: A case study of a post-graduate university course. Proceedings AusWeb97. [viewed 6 Oct 1998]

http: / / ausweb.scu.edu.au/proceedings/agostinho/index.html

Alexander, S. \& Hedberg, J. (1994). Evaluating technology-based learning: Which model? In K. Beattie, C. McNaught \& S. Wills (Eds), Interactive multimedia in university education: Designing for change in teaching and learning (Vol. A 59, pp. 233-244). Amsterdam: Elsevier B. V. (North Holland).

Alexander, S., McKenzie, J. \& Geissinger, H. (1998). An evaluation of information technology projects for university learning. Canberra: Australian Government Publishing Service.

Australian Vice-Chancellors' Committee. (1996, 9 October). Exploiting information technology in higher education: An issues paper. [1997, 10 February] http:/ / www.avcc.edu.au/avcc/pubs / eitihe.htm

Bailey, N., Bromage, A. \& Creer, A. (2000). My.University: Personalized portals in Perl. In J. Orwant (Ed.), Proceedings of the Perl Conference 4.0 (pp. 51-59). Monterey, California, USA: O'Reilly \& Associates.

Bain, J. (1999). Introduction. Higher Education Research \& Development, 18(2), 165172.

Beck, K. (1999). Extreme programming explained: Embrace change. New York: Addison-Wesley.

Biggs, J. (1999). Teaching for quality learning at university. Buckingham: Society for Research into Higher Education \& Open University Press. 
Burkhardt, H. (1992). Classroom observation in courseware development. International Journal of Educational Research, 17, 87-98.

Carroll, J. M. (1995). Introduction: The scenario perspective on system development. In J. M. Carroll (Ed.), Scenario-based design: Envisioning work and technology in system development (pp. 1-18). New York: John Wiley and Sons, Inc.

Freeman, M. (1997). Flexibility in access, interaction and assessment: The case for web-based teaching programs. Australian Journal of Educational Technology, 13(1), 23-39.

Freeman, M. A. \& Capper, J. M. (1999). Exploiting the web for education: An anonymous asynchronous role simulation. Australian Journal of Educational Technology, 15(1), 95-116. http:/ / cleo.murdoch.edu.au/ajet/ ajet15 / freeman.html

Jonassen, D. H. \& Rohrer-Murphy, L. (1999). Activity theory as a framework for designing constructivist learning environments. Educational Technology, Research and Development, 47(1), 61-79.

Kennedy, D. M. \& McNaught, C. (1997). Design elements for interactive multimedia. Australian Journal of Educational Technology, 13(1), 1-22.

Kennedy, G. E. (1999). Defining the dimensions of a formative evaluation program: A multi-method, multi-perspective approach to the evaluation of multimedia. In B. Collis \& R. Oliver (Eds), ED-MEDIA \& ED-TELECOM 99. Proceedings of the 11th World Conference on Educational Multimedia and Hypermedia \& World Conference on Educational Telecommunications, Seattle (pp. 604-609). Charlotteville: AACE.

Kennedy, P., McNaught, C. \& Nicolettou, A. (1998). Flexible and AGILE. In B. Corderoy (Ed.), FlexibilITy: The next wave? ASCILITE 98. Proceedings of the 15th Annual Conference of the Australasian Society for Computers in Learning in Tertiary Education (pp. 397-406). Wollongong: University of Wollongong.

Laurillard, D. \& Margetson, D. (1997). Introducing a flexible learning methodology: Discussion paper (Publication No. 7). Brisbane: Griffith University: Griffith Institute for Higher Education.

Maslen, G. (2000, 9-15 August). My.uni - linking online students. Campus Review, 10-11.

McKenzie, W \& Murphy, D. (2000). "I hope this goes somewhere": Evaluation of an online discussion group. Australian Journal of Educational Technology, 16(3), 239-257.

McNaught, C., Phillips, R., Rossiter, D. \& Winn, J. (2000). Developing a framework for a useable and useful inventory of computer-facilitated learning and support materials in Australian universities (Evaluations and Investigations Program report 99/11). Canberra: Department of Employment, Education, Training and Youth Affairs. http: / / www.detya.gov.au/highered/eippubs.htm\#99_11

Moonen, J. \& Schoenmaker, J. (1992). Evolution of courseware development methodology: Recent issues. International Journal of Educational Research, 17, 109-121.

Naidu, S., Ip, A. \& Linser, R. (2000). Dynamic goal-based role-play simulation on the web: A case study. Educational Technology E Society, 3(3). http://ifets.ieee.org/periodical/vol_3_2000/v_3_2000.html 
Oliver, R. \& Omari, A. (1999). Using online technologies to support problembased learning: Learners' responses and perceptions. Australian Journal of Educational Technology, 15(1), 58-79.

Phillips, R., Bain, J., McNaught, C., Rice, M. \& Tripp, D. (2000, April 10, 2000). Handbook for learning-centred evaluation of computer-facilitated learning projects in higher education (1), [Report]. ASCILITE. [2001, 12 March] http: / / cleo.murdoch.edu.au/projects / cutsd99/ handbook/handbook.htm

Phillips, R. A. (1997). A developer's handbook to interactive multimedia: A practical guide for educational applications. London: Kogan Page.

Pressman, R. S. (1997). Software engineering: A practitioner's approach. (Fourth ed.). New York: McGraw-Hill Companies Inc.

Reiser, R. A. \& Kegelmann, H. W. (1996). Computer software evaluation. In T. Plomp \& D. P. Ely (Eds), International Encyclopedia of Educational Technology (2nd ed., pp. 257-260). Oxford: Elsevier Science Ltd.

Stade, M., Murphy, D., Webster, L. \& James, D. (1999). Review of Monash Portal. Melbourne: Monash University.

\section{Acknowledgements}

With special thanks to the members of the core development teams: Technical Development Team: Nathan Bailey (Technical Team Leader), Andrew Bromage, Andrew Creer, Mark Ridgway and Stephen Balogh, and the Client Liaison Team: Emily Feher (Client Liaison Team Leader), Anna Treasure and Gabriel Anderson.

David M Kennedy < david.kennedy@celts.monash.edu.au>

Formerly Centre for Learning and Teaching Support

Monash University, Melbourne

Len Webster <len.webster@law.monash.edu.au>

Faculty of Law, Monash University, Melbourne

Robyn Benson <robyn.benson@celts.monash.edu.au>

Centre for Learning and Teaching Support, Monash University, Melbourne

Di James <di.james@adm.monash.edu.au>

Office of the Deputy Vice Chancellor, Monash University, Melbourne

Nathan Bailey < Nathan.Bailey@its.monash.edu.au>

Information Technology Services, Monash University, Melbourne

An earlier version of this article was published under:

Kennedy, D., Webster, L., Benson, R., James, D. \& Bailey, N. (2001). The

Monash portal: More than just a virtual gateway. In G. Kennedy, M.

Keppell, C. McNaught \& T. Petrovic (Eds), Meeting at the Crossroads.

Proceedings of the 18th Annual Conference of the Australasian Society for

Computers in Learning in Tertiary Education. (pp. 317-326). Melbourne:

Biomedical Multimedia Unit, The University of Melbourne.

http:/ / www.medfac.unimelb.edu.au/Ascilite2001/pdf/ papers/kennedyd.pdf 